\title{
RELIABILITY-BASED RISK FACTORS
}

\author{
David G. Elms*
}

\section{SYNOPSIS:}

Risk factors are used in some codes to allow for the higher than normal consequences of the failure of essential or important structures. A classification of high-risk structures is given, based on different reasons for high importance. Risk factors are then related to reliability factors, defined as the increases in reliability required compared with that for a normal building. By assuming reasonable values for reliability factors, a set of risk factors is derived. Some of these correspond closely to those specified in the New Zealand code, while others differ markedly.

\section{IINTRODUCTION:}

The provisions of any building code will often appear inconsistent, inadequate, confusing and difficult to interpret: We may call this "code uncertainty". Such difficulties should be expected, for a degree of uncertainty is inherent in the code-writing process. No matter how well code writers work, they cannot reduce the code uncertainty below a certain level. There are two reasons for this. Firstly, although the physical loadings applying demands to a structure and also the responses of the structure itself are exceedingly complex phenomena, codes must necessarily treat the situation in a relatively simple manner, both for practical reasons and because the uncertainty of present knowledge does not justify a more complex approach. There is thus an inherent mismatch in complexity between physical behaviour and code idealisation. This will frequently appear as an inconsistency or area of confusion in the code. Secondly, although a code generally appears to be a technical and objective document dealing with practical matters of design, in reality its provisions must also take into account underlying psychological and sociological values which are very hard to define, let alone quantify. Moreover, in a society as well as in an individual, these values are constantly shifting and the concepts associated with them are difficult to grasp. Indeed, it has been well said that the philosophical

difficulties of engineering are at present greater than the technical difficulties $(7,8)$. For these reasons, too, a code must contain an inherent level of uncertainty.

It is hardly surprising, therefore, that there is often a degree of uncertainty and sometimes misunderstanding associated with the importance and risk factors, I and $R$, given in the seismic provisions of the New Zealand Loadings Code, NZS4203 (1).

* Professor of Civil Engineering, University of Canterbury, Christchurch, New Zealand
Not only is seismic design especially complex, but also the importance and risk factors attempt to deal with the external consequences of structural failure and so must be particularly concerned with the values placed by society on these consequences. However, because the two factors are relatively independent of the rest of the code, an investigation into their definition and levels is appealing.

\section{IMPORTANCE AND RISK:}

Importance and risk factors are introduced into the seismic provisions of NZS4203 to take into account the fact that failures of some structures will have greater consequences than those of others. The difference between the two factors is that the importance factor is intended to be concerned with the social and economic importance attached to the survival and functionality of a building, while the risk factor reflects situations in which a single instance of structural failure could lead to a high loss of life.

The current code classifies buildings according to importance factor as follows. Buildings are divided into three classes. Class I buildings are "essential facilities required to be completely functional immediately following an earthquake disaster". This definition is straightforward, and it is generally obvious which structures should be included in the category. The code gives examples of typical essential facilities; among these are civil defence and civilian emergency centres, fire stations, hospitals, electricity supply substantions and radio and television facilities. Class II buildings are described as "Public buildings not included in Class I". There is more difficulty associated with this definition because the intent of the classification is not stated: we do not know exactly what is meant by "public buildings", nor are we told bhy they should be singled out. The code lists some typical class II buildings, and it seems that, with a few exceptions, "public buildings" should be regarded as publicly owned buildings. 
As there is no obvious rational basis for such a definition, this classification needs some investigation. Finally, Class III buildings are defined as any buildings not included in either of the previous two classes.

The code designates four levels of risk factor. Apart from normal risk buildings with a factor of 1.0 , a factor of 1.1 is assigned to assembly buildings and buildings accommodating more than 1000 people, presumably to reduce the possibility of a large number of people being killed by the collapse of a single structure. Damage to structures containing distribution facilities for gas or petroleum products in urban areas may constitute a severe fire or explosion hazard, and so this class of building is assigned the reasonably high factor of 2.0. The final class, with a risk factor of 3.0 , applies to to "structures and installations for the direct support or containment of toxic liquids or gases, spirits, acids, alkalis, molten metal or poisonous substances..." clearly, this category addresses a number of different hazardous situations ranging from, say, a molten metal container, a minor failure of which might result in the rather unpleasant death or injury of people nearby, to failure of a gas or inflammable spirit container which could lead to a large and dangerous explosion or fire.

A number of difficulties are associated with the present code definitions of importance and risk. Firstly, although the importance and risk factors are aimed at different aspects of the external consequences of structural failure, namely, socioeconomic importance and hazard level, in practice the two aspects are not mutually exclusive and a signle structural failure can have effects in both areas. Failure of a civil defence centre or a hospital could indirectiy lead to a serious increase in the number of deaths following a severe earthquake, and so such structures contribute to "risk" even though they are not considered in the code risk factor classification. Similarly, gas or petroleum distribution facilities are important to the functioning of society as well as being hazardous, but in the code they are only condisered in the risk factor category. In some cases a building could be assigned a risk factor and an importance factor which are both greater than unity: an assembly building, for instance, could also be part of a local government centre or be a designated civil emergency centre. It is doubtful whether the application of both factors to the same building could be rationally justified; for as the purposes of the two factors are distinct, the higher factor would automatically achieve the intent of the lower, and the product of both, as required by the code, would result in an unjustifiably high overall factor.

These arguments imply that it would be more correct to combine the importance and risk factors into one single factor reflecting all the external consequences of failure, whether socioeconomic or hazard-related.

Other codes in general have only a single factor, if they consider the consequences of failure at all. The 1973 SEAOC code (14) makes no provision for such effects, while the later ATC-3 draft code (17) divides buildings into three seismic hazard exposure groups: the definitions of these groups are given in Table I below. It is of interest to note that the ATC-3 seismic hazard exposure groups are not used to factor the design base shear coefficient, but rather, they are used as the basis of different detailing requirements. This approach is appropriate in the United states, where large areas of the country are subject to negligible seismic risk. In New Zealand, seismic detailing is required in all areas, and so the use of a risk or importance factor is appropriate. The 1976 Mexican Code (15) uses a single risk factor.

The present New Zealand Code shows a degree of vagueness in the definition of buildings appropriate to each category of the $I$ and $R$ factors. This comes about largely because, with the exception of the importance factor of Class I buildings, the intent of the factors is not spelled out. There are, for instance, a number of "public buildings" in the sense of publicly-used buildings, such as banks and food stores, which are essential for the functioning of a community but which are not publicly-owned, and hence do not appear in the code commentary list of typical class II buildings.

A further problem is the question of the numerical values assigned to the importance and risk factors. These appear to have been chosen on the basis of engineering judgement only. According to Rosenblueth (15) an optimisation analysis was carried out in order to set the appropriate level of the factor for essential facilities included in the 1976 Mexican code. This factor has the surprisingly low value of 1.3 , in contrast with the value of 1.6 used in the New Zealand code. A different optimisation approach has been used by the Author (5) to relate risk factors to the cost consequence of failure. The present paper investigates the matter by relating risk factors to changes in the probability of failure of a structure.

\section{CLASSIFICATION OF IMPORTANCE AND RISK}

As mentioned earlier, difficulties arise in the interpretation of the importance and risk factors in the present code because, with the exception of Class I buildings, the intent of the code is not clearly stated. In order to achieve a set of clear, consistent, mutually exclusive and as far as possible specific aims for this aspect of the Code, various areas with which the code should properly be concerned will be considered. 
First, there is the matter of reducing, for a community, the social and economic consequences of a severe earthquake. Understanding of the nature of a society's response to a disaster has been increased by a descriptive model put forward by Kates and pijawka (6, chapt. 1). The model divides disaster recovery into four overlapping periods called the Emergency Period, the Restoration Period, the Replacement Construction Period and the Commemorative, Betterment and Development Reconstruction Period. The first two, and to a lesser extent the third, of the these periods are pertinent to an earthquake code. Popkin's (6) description of the first three post-disaster periods is:

The emergency period is the time in which the community copes with problems caused by the extent of the destruction and the number of dead, injured, homeless and missing. Normal social and economic activities are disrupted. Depending on a community's ability to cope, this period may last only days or a few weeks. Typical indicators of the end of the emergency are cessation of search and rescue, drastic reduction in emergency mass feeding and housing, and clearance of debris from principal streets.

The restoration period is marked by the patching up of public utilities, housing, commercial and industrial structures which can be restored, and the return to relatively normal social and ecomonic activities. In societies with ample resources, this period may extend over a few months. The end of the restoration period is marked by the return of major urban services, utilities and transport, the return of evacuees intending to return, and substantial removal of rubble.

During the replacement reconstruction period, the city's capital stock is rebuilt to predisaster levels, and social and economic activities return to predisaster levels or higher. The end of the period is marked by the replacement of population and the functional equivalent of their needs for homes, jobs, capital stock and urban activities. Some aspects of reconstruction may continue long after the period is over if large-scale construction projects are involved.

Kates and Pijawka comment that each of these periods lasts for approximately ten times the length of the previous period. The time each period lasts will also depend on the severity of the earthquake. For a severe earthquake the emergency and restoration periods could extend over a very considerable time, while for a moderate earthquake the two periods will be much shorter and the economy of the region will be speedily restored.

Code aims related to socioeconomic consequences can be linked to the KatesPijawka model. It can be seen that Class I buildings as defined in the existing code are buildings which must be functional throughout the Restoration Period.

Another matter to be considered in the socioeconomic area is the response of a community to a moderate earthquake. Although the Kates-Pijawka model applies in general terms, the specific descriptions of the various periods will be considerably different. In particular, although the economic damage might be considerable it would not be sufficiently great to require large-scale evacuation of the population following the earthquake. The types of facility which would have to be fully functional in the restoration period would therefore be different as they would have to cater for a much larger number of people.

A further area of interest is the question of safeguarding items to which the community ascribes a high level of value. These may not necessarily have a high monetary value: They might, for instance, be archives, historical artifacts, art collections, museums or historical buildings.

Loss of life is regarded as a serious matter in western societies. If the collapse of a single structure might lead to a high loss of life, the code must allow for such greater consequences of failure by increasing the safety level of the structure. This is made more important by the fact that the serious, ness with which people regard loss of life is markedly nonlinear: For instance, a single disaster in which 10 people are killed is thought of as being far more serious than 10 separate instances in which one death occurs. In trying to formulate code provisions to allow for these matters, a further point to be considered is that people tend to accept a far higher level of risk voluntarily than they do involuntarily $(8,16)$. This implies that the owner of a building - of a home, for instance - would accept, and perhaps even expect a lower level of safety than the occupants of a public or commercial building. of Iife by

Structural failure can cause loss

(a) collapsing, and killing occupants;

(b) partly failing, and trapping injured occupants in buildings with limited exits, such as high-rise buildings:

(c) causing explosions, fires and the like, killing people in surrounding areas.

Categories (a) and (b) are well described by the ATC- 3 definition of Group II buildings (Table I): "... buildings having a large number of occupants or buildings in which the occupants' movements are restricted or their mobility is impaired". The examples of Group II facilities also quored in Table I are interesting. 
TABLE 1 - SEISMIC HAZARD EXPOSURE GROUPS (FROM ATC-3)

All buildings shall be assigned to one of the following Seismic Hazard Exposure Groups for the purpose of these provisions:

(A) GROUP III. Seismic Hazard Exposure Group III shall be buildings having essential facilities which are necessary for post-earthquake recovery. Essential facilities, and designated systems contained therein, shall have the capacity to function during and immediately after an earthquake. Essential facilities are those which have been so designated by the Cognizant Jurisdiction. Access to essential facilities shall conform to the requirements of $\mathrm{Sec} .1 .4 .2(E)$.

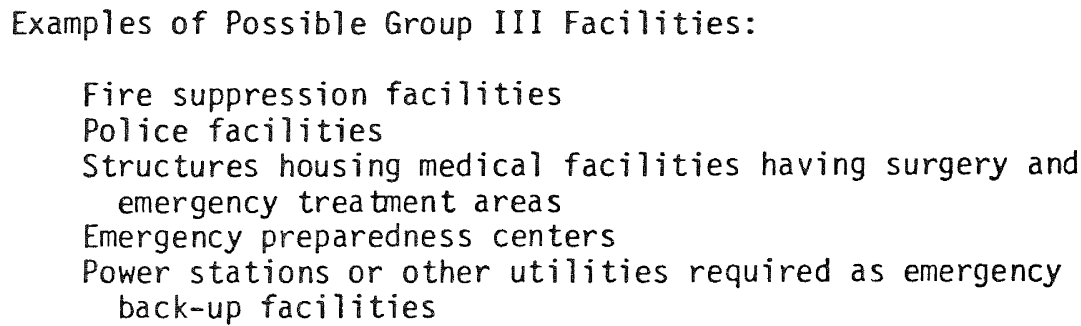

(B) GROUP II. Seismic Hazard Exposure Group II shall be buildings having a large number of occupants or buildings in which the occupants' movements are restricted or their mobility is impaired.

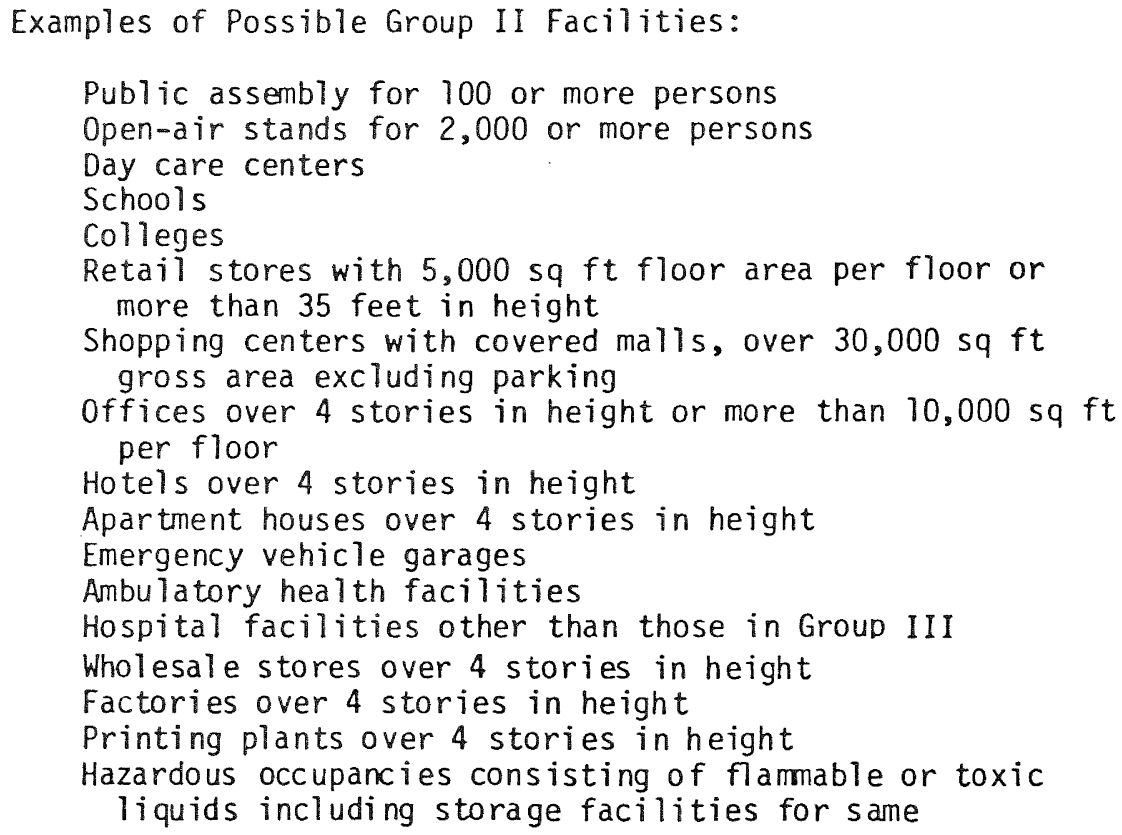

(C) GROUP I. Seismic Hazard Exposure Group I shall be all other buildings not classified in Group III or II.

(D) MULTIPLE USE. Buildings which have multiple uses shall be as signed the classification of the highest Seismic Hazard Exposure Group which occupies 15 percent or more of the total building area.

(E) PROTECTED ACCESS. Buildings as signed to Se ismic Hazard Exposure Group III shall be accessible during and after an earthquake. Where access is through another structure that structure shall conform to the requirements for Group III. Where access is within 10 feet of side property lines, protection against potential falling hazards from the adjacent property shall be provided. 
Also to be borne in mind when considering the subject of safety is the possible failure in a moderate earthquake of structures containing or supporting highly hazardous contents such as petrol, acids, toxic liquids or molten metals. Even a small spillage of such liquids could cause serious injury or death. And, of course, structures of this nature should be extremely safe in a severe earthquake.

Before trying to suggest code provisions covering all these points, it is necessary to attempt to achieve some understanding of the levels of safety factor which would be required. The only attempt at providing a theoretical derivation of safety factor levels known to the Author is an optimisation exercise carried out for the 1976 Mexican Code (15). This resulted in the surprisingly low factor of 1.3 for essential facilities. In the next section, a different approach is taken in which factors of safety are related to the changes they produce in probabilities of failure. The aim of this is to provide some understanding of the meaning of different safety factor levels.

\section{FAILURE PROBABILITY AND CODE FACTORS}

The New Zealand Code design equation for earthquake loading (1, Eq.4) can be written in the general form

$\phi U^{*}=\gamma_{D} D^{*}+\gamma_{L} L^{*}+R \gamma_{E} E^{*}$

where $U^{*}, D^{*}, L^{*}$ and $E^{*}$ are nominal (code) values of resistance and of dead, live and earthquake loads respecively. $\phi$ is a capacity reduction factor, $\gamma_{D}, \gamma_{T}$ and $\gamma_{\mathrm{F}}$ are load factors and $R$ is a "risk factor" whose effects we shall investigate. This factor covers the intentions of both the importance and the risk factors of the present code. Let the relation between the mean and the nominal values of a quantity be of the form

$M_{X}=B_{X} X^{*}$

and let the standard deviation of quantity $\mathrm{X}$ be $\sigma_{\mathrm{y}}$. Let us define a reliability index $\widehat{B}_{C}$ as

$\beta_{C}=\frac{M_{U}-M_{S}}{\sqrt{\sigma_{U}^{2}+\sigma_{U}^{2}}}$

where ${ }^{M_{U}}$ and ${ }^{M_{S}}$ are the mean values of resistance and load respectively, This definition of the reliability index was first given by cornell (2): since then, a number of other definitions have been suggested, with different advantages and disadvantages. In various ways Cornell's index is not ideal - it is not constant, for instance, under transformations of variables $(4,11)$ - but we shall use it because of its simplicity.

Following Ravindra, Lind and Siu(13) we can combine Eqs, 1, 2 and 3 to give

$$
\beta_{C}=\frac{\begin{array}{l}
\left(\psi_{U} \gamma D-B_{D}\right) D^{*}+\left(\psi_{U} \gamma_{L}-B_{L}\right) L^{*}+ \\
\left(\psi_{U} \gamma_{E}^{R}-B_{E}\right) E^{*}
\end{array}}{\sqrt{\sigma_{U}^{2}+\sigma_{D}^{2}+\sigma_{L}^{2}+\sigma_{E}^{2}}}
$$

where $\psi_{\mathrm{U}}=\mathrm{B}_{\mathrm{U}} / \phi$. Using Lind's "separation factor" $\alpha(9,10)$, where

$\alpha(1+x)=\sqrt{1+x^{2}}$

and noting that the standard deviation of the resistance may be written

$\sigma_{U}=V_{U} \psi_{U}\left(\gamma_{D} D^{*}+\gamma_{L} L^{*}+R \gamma_{E} E^{*}\right)$

where $V_{U}$ is the coefficient of variation of the resistance, the risk factor can be expressed explicitly as

$R=\frac{\left(B_{D}-K \gamma_{D}\right) D^{*}+\left(B_{L}-K \gamma_{L}\right) L^{*}+B_{E} E^{*}+B_{C} C}{K \gamma_{E^{*}} E^{*}}$

where

$\mathrm{K}=\psi_{\mathrm{U}}\left(1-\alpha \beta_{\mathrm{C}} \mathrm{VU}\right)$

and

$C=\alpha \sqrt{\sigma_{D}^{2}+\sigma_{L}^{2}+V_{E}^{2} B_{E}^{2} E^{2}}$

In order to examine the sensitivity of the probability of failure of a structure (or, more generally, of attainment of a limit state) to changes in the risk factor $R$, it is first necessary to relate $B$ to the probability of failure. We shall then require the sensitivity of $R$ to changes in $\beta$. The factor by which $R$ should be multiplied to cause a unit change in $\beta_{C}$ is

$F_{B}=I+\frac{I}{\bar{R}} \frac{\partial R}{\partial \beta}$

Differentiating $\mathrm{Eq}$, 7 and substituting, we obtain

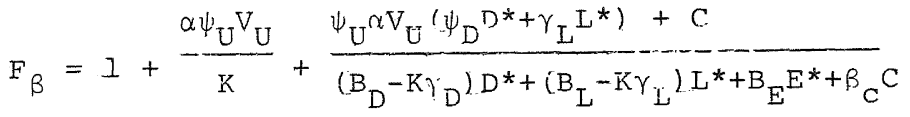

The behaviour of this relationship may be explored by examining the effects of perturbations from a basic result obtained for a particular building. The standard structure is assumed to be a 3 -storey reinforced concrete frame building with a $6 \mathrm{~m}$ bay width, and the bending moment resistance at the ends of one of the beams will be considered. The dead load is assumed to be $4.8 \mathrm{kPa}$, leading to $D^{*}=43.2 \mathrm{kNm}$. $\mathrm{B}_{\mathrm{D}}$ is taken as 1.0 . In the case of an earthquake it can be assumed that the live load acting at the time is the mean of that found by various surveys (3), or $0.60 \mathrm{kPa}$. From NZS4203, 


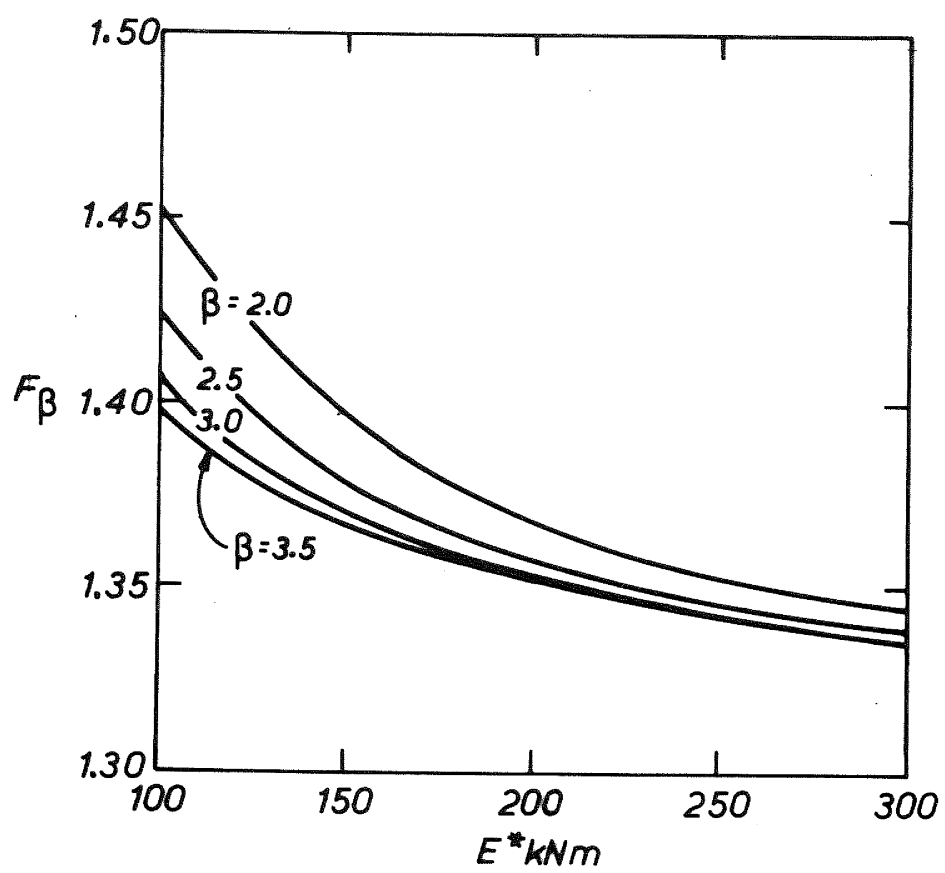

FIG. 1

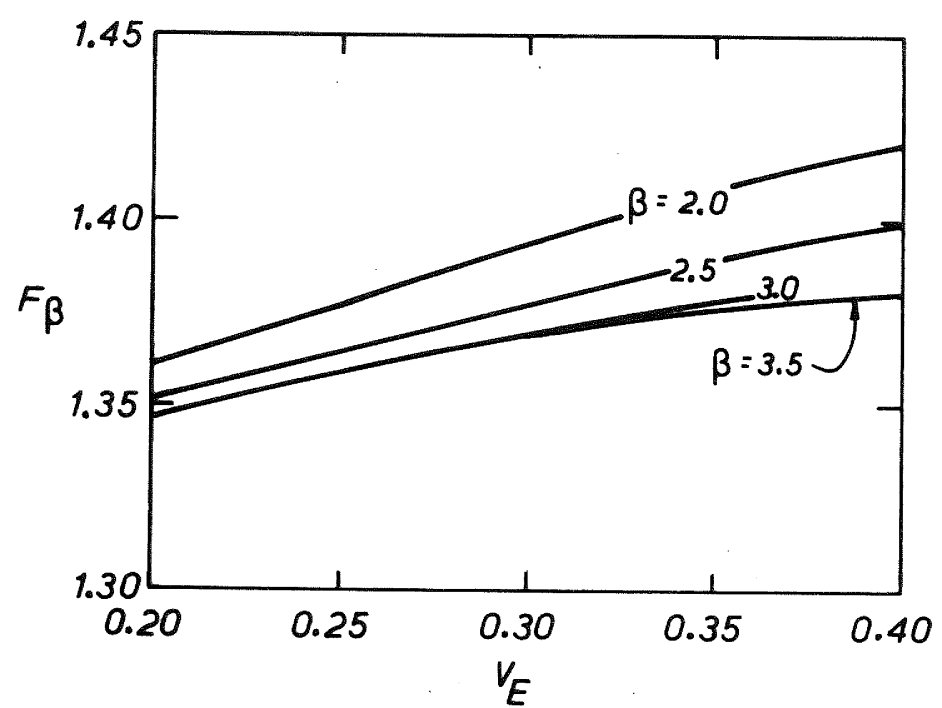

FIG. 3

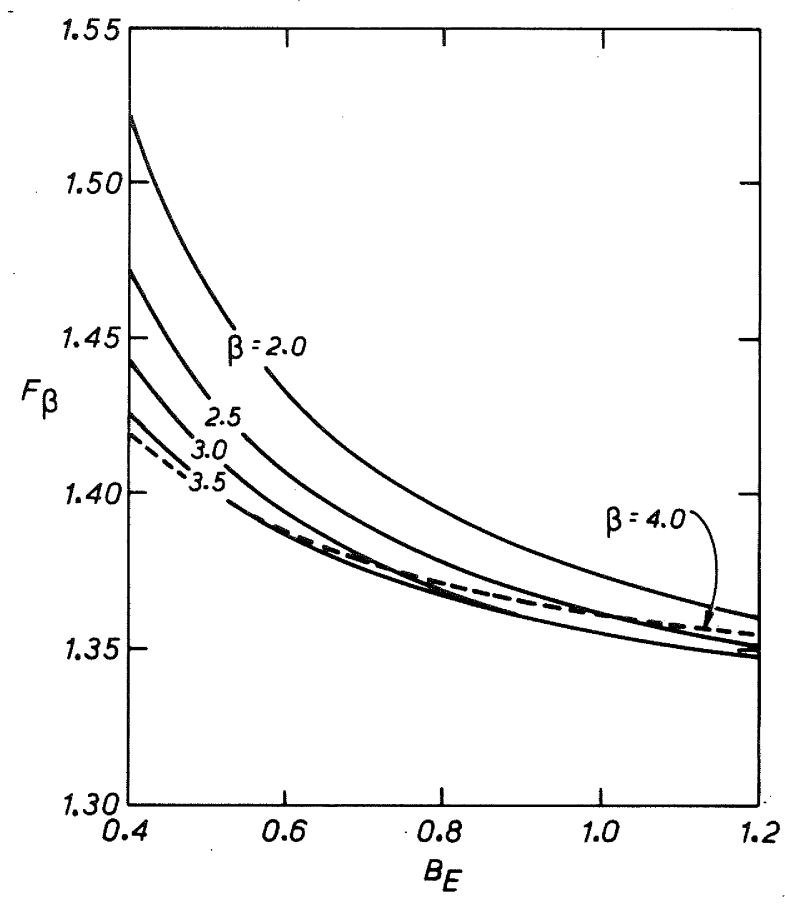

FIG. 2

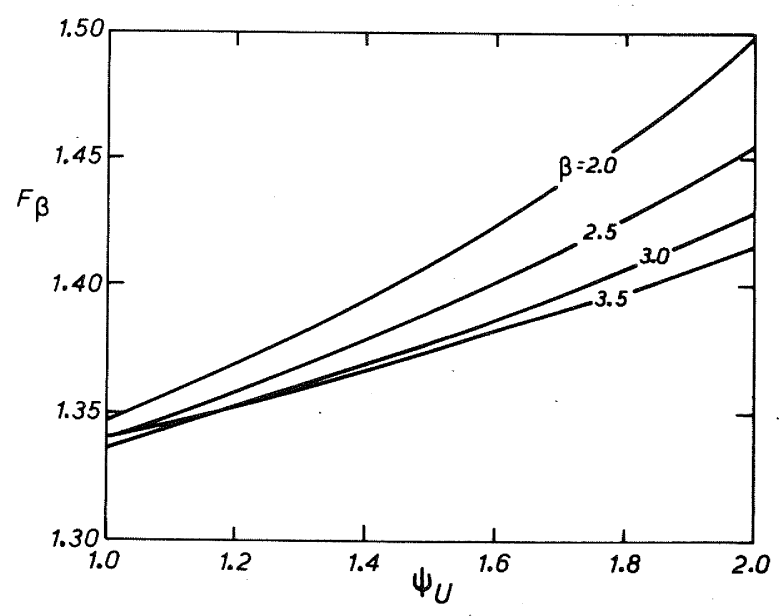

FIG. 4 
the reduced live load is $2.0 \mathrm{kPa}$ from which $L^{*}=18.0 \mathrm{kNm}$ and $B_{T}=0.6 / 2.0=0.3$. The computed earthquake moment is taken to be $150 \mathrm{kNm}$. The value of $\mathrm{B}_{\mathrm{T}}$ is difficult to decide. Even if Seismic behaviour were better known, the difficulty of estimating a quasi-static load equivalent to the motion of a particular earthquake is considerable. We shall assume $\mathrm{B}_{\mathrm{F}}=0.8$, and as there is uncertainty about this figure, it will be varied over a suitable range. Coefficients of variation for dead and live load are estimated by Ravindra, Lin and Siu (13) to be $V_{0}=0.11$ and $V_{1}=0.32$. We estimate the coefficient of variation for earthquake loading to be 0.3 , but because of the uncertainty involved this figure will be varied. Work by Paulay (12) suggests taking $\psi_{U}=$ 1.39, and we shall use Ravindra, Lind and Siu's estimate of $V_{U}=0.15$. The usual value of the separation factor $\alpha$ is 0.75 , and the New Zealand Code gives values of $1.0,1.3$ and 1.0 for $\gamma, \gamma$ and $\gamma$ respectively. Our standárd Value for the reliability index will be $\beta_{c}=3.0$. It should be noted that this value Is lower than that sometimes quoted for the calculation of reliability, because in this case it is a conditional index; that is, it is related to the probability of failure given that a severe (design) earthquake has occurred. In fact, evaluation of $\mathrm{Eq}$. 4 using the information given above leads to a value of $\beta_{C}=2.3$.

Figures $1-7$ show how $F_{B}$ varies with the various parameters concerned. $F_{\beta}$ can be interpreted as the value of the risk factor $\mathrm{R}$ to produce a unit change in $\beta$. It can be seen that in general $F_{B}$ is not very sensitive to changes in any of the variables, and maintains a value of about 1.38. However, low values of $B_{B}$ lead to significant increases in $F_{B}$. while for $\beta$ greater than $3.0, F_{\beta}$ increases rapidly for high values of $V_{t}$. Fortunately, the conditional reliability index we are concerned with here is likely to be lower rather than higher than 3.0 .

If the probability distributions of load and resistance are known, which involves knowing the appropriate models and in most cases specifying two parameters for each, such as the means and the standard deviations, then the probability of failure can be computed by numerical integration. In addition, $\beta$ can be obtained from Eq. 3 . Figures 8-1i show how $\beta$ varies with the probability of Eailure, $\mathrm{C}_{f}$. Three

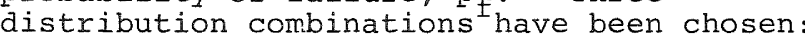
the resistance is always assumed to be normally distributed, while the load distributions are normal, lognormal and extreme type I. The mean value of the load is always assumed to be 100, while the mean value of resistance varies according to the implied level of safety. The standard deviations of both load and resistance are given different values.

The relationship between $\beta_{C}$ and $p_{f}$ can be linearised to a fair degree of accuracy in the form
$B_{C}=A+B \log _{10}\left(\frac{1}{p_{f}}\right)$

Values of the coefficients $A$ and $B$ are given in Table II.

Coefficient $B$ may be interpreted as the amount by which $\beta$ must be increased in order to diminish ${ }^{C}$ the probability of failure by a factor of 10 . The choice of an appropriate value of $B$ is difficult. The standard deviations of resistance/load (for a load of 100) are likely to be nearest to $30 / 30$ or $50 / 30$. Thus a compromise value for $B$ assuming that the load has either a lognormal or extreme type I distribution is about 1.05. This is considerably higher than the value corresponding to an assumption of normally distributed load, but such a distribution would be unlikely.

We can thus estimate that the value of the risk factor $R$ that would alter the probability of failure by a factor of 10 should be $(1.05) \times(1.38)=1.45$ This figure provides a basis for the choice of risk factors once various categories of structure can be related to the relative probability of failure for which the structure should be designed. If we define a "reliability factor" $P$ as the factor by which the probability of failure is to be reduced, the corresponding risk factor is given by

$R=1.0+0.45 \log _{10}(P)$

Typical values are given in Table III.

\section{RISK CATEGORIES AND CODE RISK FACTORS}

Section 3 of this paper described various categories of buildings with greater than normal consequences of failure. These have been listed in Table IV: reliability factors have been assigned to them, and the corresponding risk factors have been computed from Eq. 13. The reliability factors have been estimated arbitrarily by the Author and represent his personal belief as to the appropriate increases in reliability that should be built into the different categories. In practice, a code committee should decide on the values to be used. Nevertheless, it is interesting to see that the resulting risk factors for categories 1,2 and 4 correspond closely to the importance factors given by NZS4203 for Class I and Class II buildings, while the factor for category 6 is very similar to the equivalent code risk factor.

However, the factors derived for categories 7 and 8 are very much lower than those given in the code.

One advantage of the present approach is that in special cases, designers could assess their own values of reliability factor and then use them to derive the risk factors they should use for design. For instance, the values of the contents of museums, libraries, art galleries and so on will vary: some will be of national importance, while others will be of 


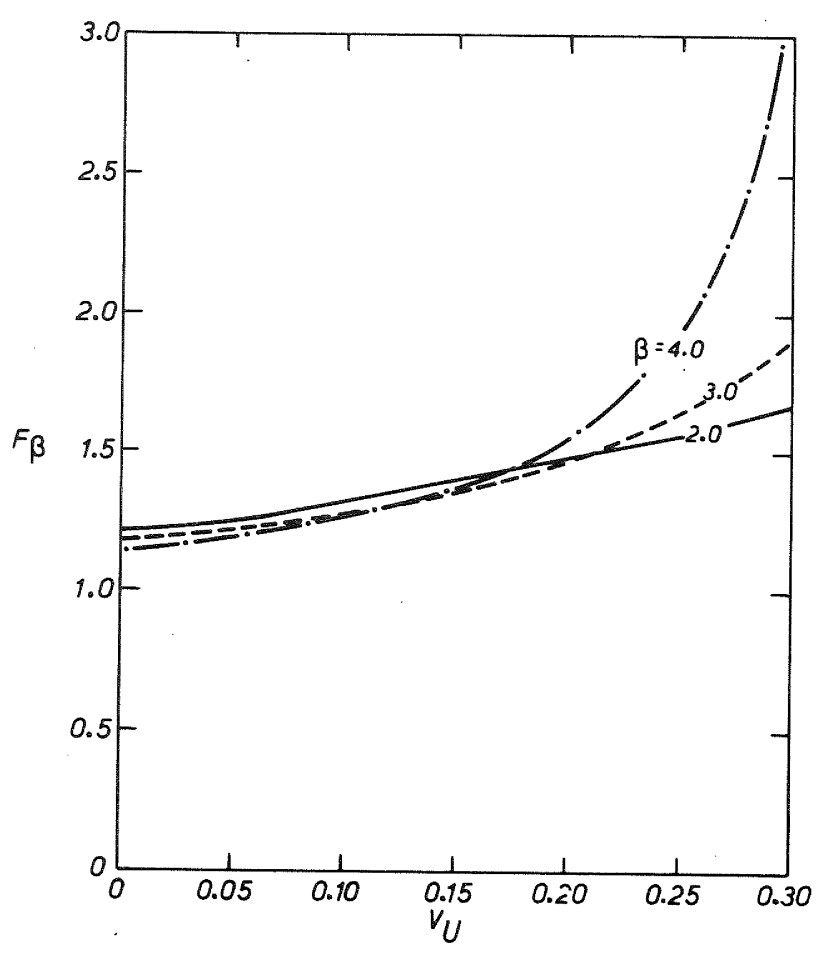

FIG. 5

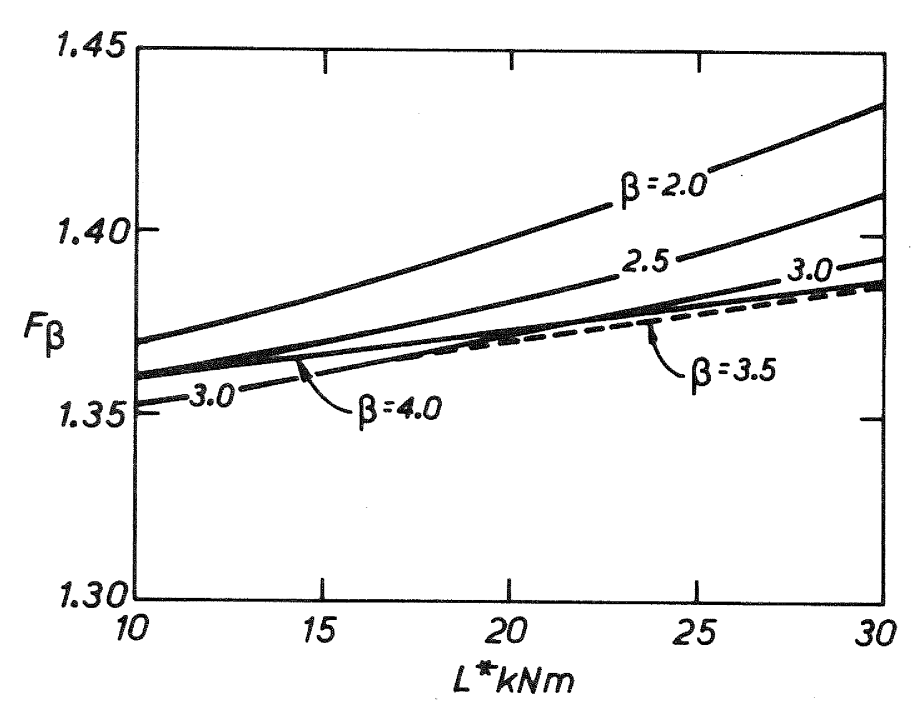

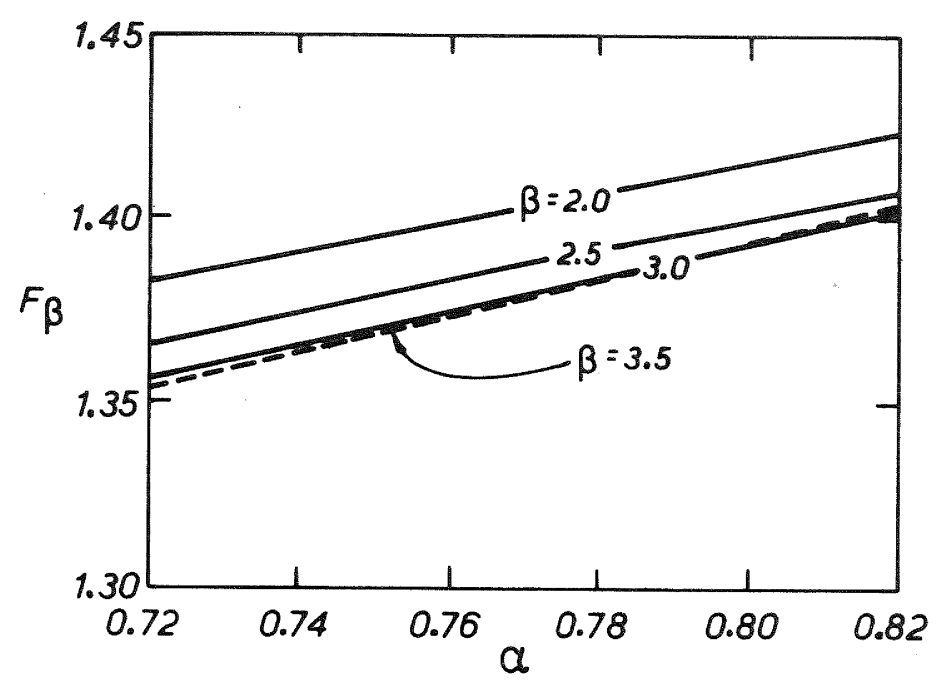

FIG. 6

FIG. 7 
TABLE III - CORRESPONDENCE BETWEEN RELIABILITY FACTORS AND RISK FACTORS

\begin{tabular}{|rl|}
\hline$P$ & $R$ \\
\hline 1 & 1.0 \\
2 & 1.14 \\
5 & 1.31 \\
10 & 1.45 \\
20 & 1.59 \\
50 & 1.76 \\
100 & 1.90 \\
1000 & 2.35 \\
\hline
\end{tabular}

TABLE IV - BUILDING CATEGORIES AND RISK FACTORS

\begin{tabular}{|c|c|c|c|}
\hline Category & Description & $\begin{array}{l}\text { Reliability } \\
\text { Factor } \\
\quad \text { P }\end{array}$ & $\begin{array}{l}\text { Risk } \\
\text { Factor } \\
\text { R }\end{array}$ \\
\hline 1 & $\begin{array}{l}\text { Buildings which must remain functional in } \\
\text { the Emergency Period for major earthquakes }\end{array}$ & 25 & 1.63 \\
\hline 2 & $\begin{array}{l}\text { Buildings which must be functioning in the } \\
\text { Restoration Period for major earthquakes }\end{array}$ & 5 & 1.31 \\
\hline 3 & $\begin{array}{l}\text { Buildings which must be functioning in the } \\
\text { Restoration Period for moderate earthquakes }\end{array}$ & 3 & 1.21 \\
\hline 4 & $\begin{array}{l}\text { Buildings whose contents have a high value } \\
\text { to the comanity }\end{array}$ & $\begin{array}{c}5 \\
\text { (varies) }\end{array}$ & 1.31 \\
\hline 5 & $\begin{array}{l}\text { Buildings containing many people whose } \\
\text { collapse could cause a high loss of life }\end{array}$ & 2 & 1.14 \\
\hline 6 & $\begin{array}{l}\text { Buildings whose failure could cause high } \\
\text { loss of life in the surrounding area }\end{array}$ & 10 & 1.45 \\
\hline 7 & $\begin{array}{l}\text { Structures supporting highly hazardous } \\
\text { contents which must not fail in a moderate } \\
\text { earthquake }\end{array}$ & $\begin{array}{c}5 \\
\text { (varies) }\end{array}$ & 1.31 \\
\hline
\end{tabular}




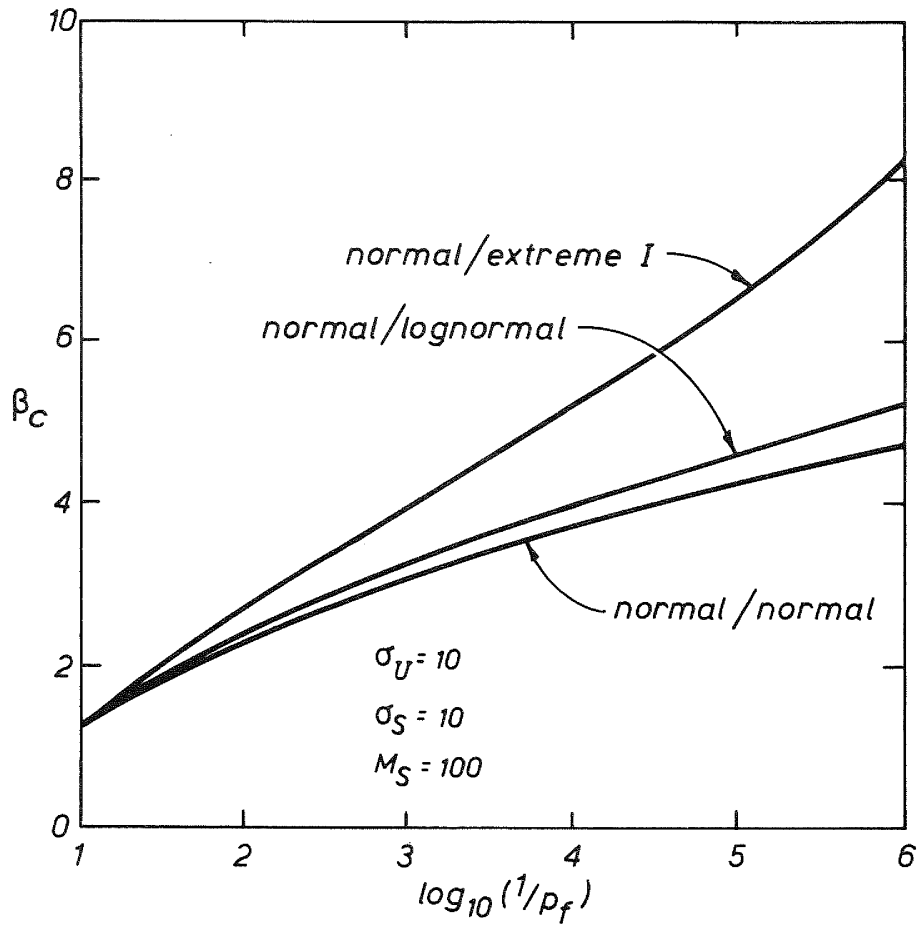

FIG. 8

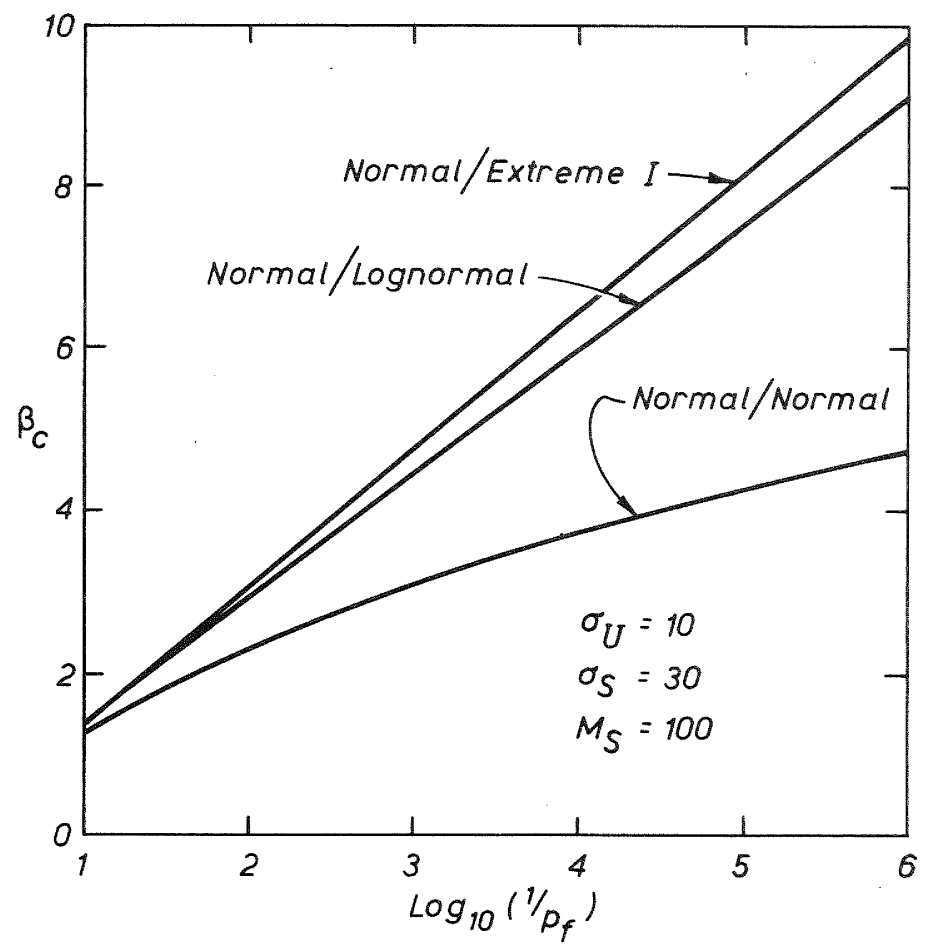

FIG. 9

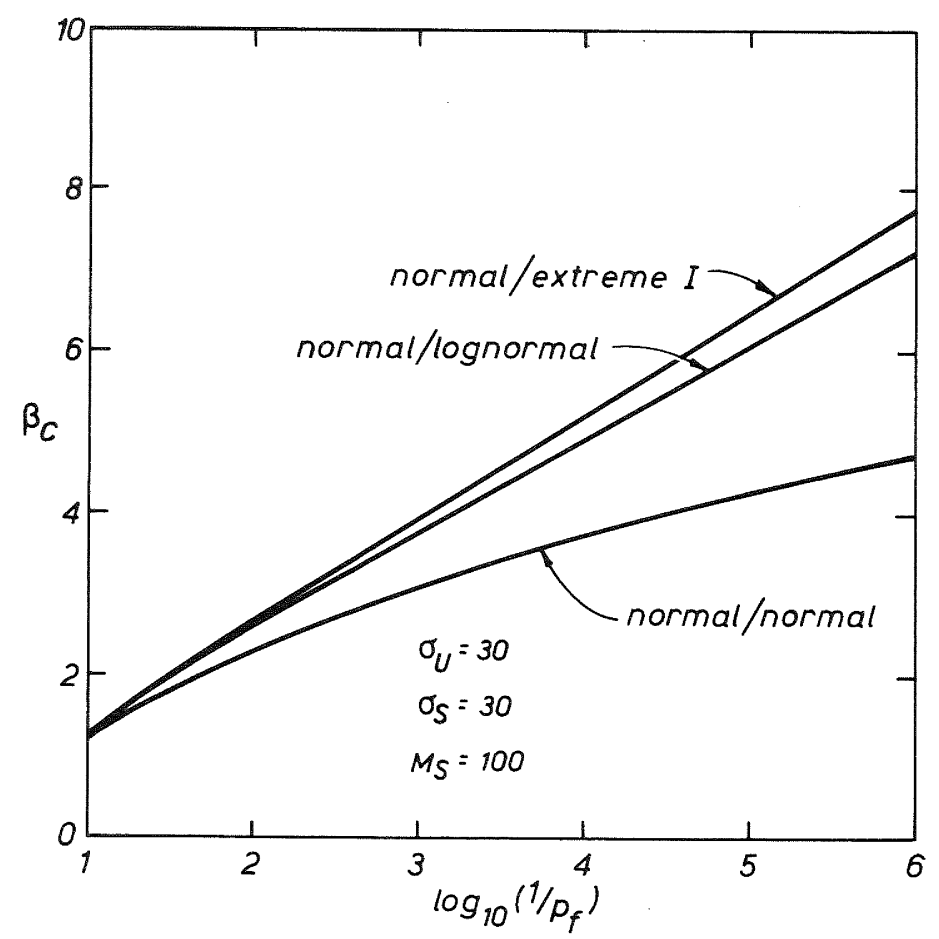

FIG. 10

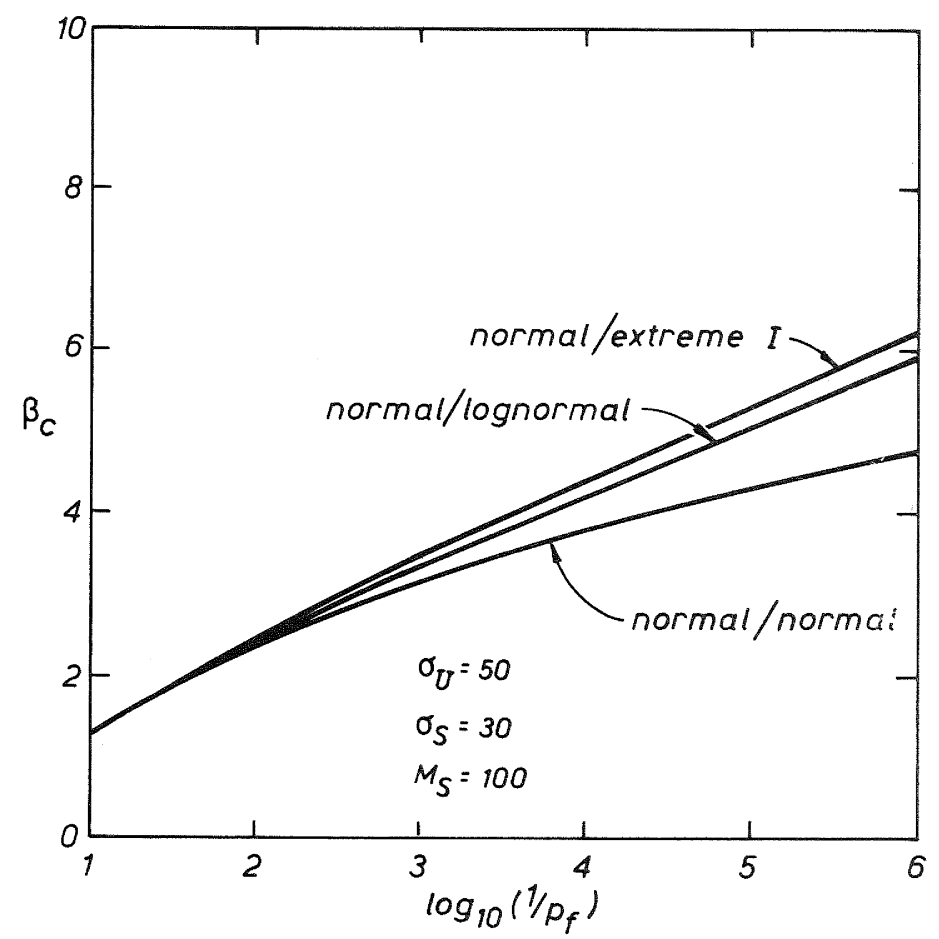

FIG. 11

RELATIONSHIP BETWEEN RELIABILITY INDEX AND PROBABILITY OF FAILURE 
lesser significance, The reliability factor could be varied for such different cases, as indicated for Category 4 buildings in Table IV.

Eq. 13 can also be used to derive the reliability factors implied by existing code factors. The New Zealand code at present requires risk factors of 2.0 and 3.0 for certain facilities and installations. The associated reliability factors are 167 and 27,800 respectively, which suggests that the risk factors are too high.

\section{CONCLUSIONS}

Two things have thus been achieved; a categorisation of buildings based upon consequences of failure, and the development of a technique relating risk factors to relative probabilities of failure, or reliability factors. The approach has been applied to a typical reinforced concrete ductile frame building in order to derive a set of risk factors; these are, however, based on the Author's estimate of an appropriate set of reliability factors.

Although a practical example has been used, further work is needed to apply the procedure to other building types, to examine in more detail the effects of parameter variations, and to develop an agreed set of reliability factors. However, it is pleasing to note that many of the derived factors correspond closely with those given in the existing New Zealand code.

The approach could also be applied to the assessment of other relative code factors, such as the structural type factors.

\section{ACKNOWLEDGEMENT :}

The Author wishes to express his thanks to David Darwin for carrying out the calculations leading to the relationships between reliability indices and probabilities of failure given in this paper.

\section{REFERENCES :}

1. Code of Practice for General Structural Design and Design Loadings for Buildings, NZS4203:1976, Standards Association of New Zealand, Wellington, 1976.

2. Cornell, C.A. - "Structural Safety Specifications Based on Second Moment Reliability Analysis", Symposium on Concepts of Structural Safety and Methods of Design, International Association for Bridge and Structural Engineering, London, England, Sept. 1969, pp. 235-246.

3. Corotis, R.B. and Doshi, V.A. "Probability Models for Live-Load Survey Results", Proc. ASCE, V 103, n.ST6, June 1977, pp. 1257-1274.
4. Ditlevsen, $0 .$, Generalised Second Moment Reliability Index, Report No. 144, Danish Center for Applied Mathematics and Mechanics, Tech. Univ. of Denmark, Lyngby, Denmark, 1978 .

5. Elms, D.G., "Rational Derivation of Risk Factors", Proc. 7th Australian Conf.. on the Mechanics of Structures and Materials, Perth Australia, 1980.

6. Haas, J.E., Kates, R.W. and Bowden, M.J. - Reconstruction Following Disaster, MIT Press, Cambridge, Mass 1977.

7. Ingles, O.G., and Saunders, J.R., "The Concept of Engineering", Proc. 2nd Int. Conf. Applications of Statistics and Probability in Soil and Structural Engineering, v II, Aachen, DGEG, 1975, pp.119-129.

8. Ingles, O.G., - "Human Factors and Error in Civil Engineering", Proc 3rd. Int. Conf. Applications of Statistics and Probability in Soil and Structural Engineering, Sydney, Australia, 1979, pp.402-417.

9. Lind, N.C. - "Deterministic Formats for the Probabilistic Design of Structures", An Introduction to Structural Optimisation, Solid Mechanics Study No. 1, Univ. of Waterloo, Canada, 1968.

10. Lind, N.C. - "Theory of Codified Structural Design", Special Publication, Solid Mechanics Div., Univ. of Waterloo, Canada, 1972.

11. Lind, N.C. - "Formulation of Probabilistic Design", Proc. ASCE, v.103, n.EM2, ApriI 1977, pp.273-284.

12. Paulay, T. - "Columns - Evaluation of Actions", Bull. N.Z. Nat. Soc. for Earthquake Engineering, v.10, n.2, June 1977, pp.85-94.

13. Ravindra, M.K., Lind, N.C. and Siu, W. - "Illustrations of ReliabilityBased Design", Proc. ASCE, v.100, n.ST9, sept. 1974, pp.1789-1811.

14. Recommended Lateral Force Requirements and Commentary, Structural Engineers Association of California, San Francisco, 1973.

15. Rosenblueth, E. - "Seismic Design Requirements in a Mexican 1976 Code", Earthquake Engineering and Structural Dynamics, v.7, n.1, 1979, pp. 49-61.

16. Starr, C. - "Social Benefit vs Technical Risk", Science, Am.Ass. Advancement Sciénce, v.165, Sept. 1969, pp.1232-8.

17. Tentative Provisions for the Development of Seismic Regulations for Buildings: ATC 3-06, Applied Technology Council, Palo Alto, Calif. 1978.

Paper Received 20 December 1979. 